\title{
Revision of the Botanophila helviana species group (Diptera: Anthomyiidae) in Europe
}

\author{
VERNER MICHELSEN \\ Zoological Museum, Natural History Museum of Denmark, University of Copenhagen, Denmark \& Museum of Zoology, Lund \\ University, Sweden.E-mail: vmichelsen@snm.ku.dk
}

\begin{abstract}
Species of the Botanophila helviana species group are small, blackish anthomyiids known from temperate to subarctic (northern/elevated) parts of the Holarctic Region. Adult flies are anthophilous, obtaining pollen and nectar from various flowering plants. Preliminary evidence suggests that the larvae may attack developing seed heads of Ranunculus (Ranunculaceae). The male and female terminalia are very characteristic and support the monophyly of the species group. Further evidence for this is provided by the peculiar structure of their prestomal teeth. A taxonomic revision of the European species with illustrated descriptions and an identification key to males and females is given. The following six species are treated: Botanophila helviana Michelsen, 1983, B. kitadakeana Suwa, 1998 and the new species B. minuta (Norway, Sweden), B. nigra (Norway, Finland and Sweden), B. peristeriensis (Greece) and B. saliciphila (Spain).
\end{abstract}

Key words: Diptera, Anthomyiidae, Botanophila, new species, Europe

\section{Introduction}

The large anthomyiid genus Botanophila Lioy is very heterogeneous, but contains several assemblages of morphologically very similar and obviously closely related species. One such assemblage is the Botanophila helviana species group proposed by Xue \& Song (2007) for species with a number of shared, derived character states of the male terminalia (see below). They named the species group after the European $B$. helviana Michelsen, 1983 and further included four Chinese endemic species: B. brevipalpis (Jin, 1983) from Gansu, B. truncata (Fan, 1988) from Xizang, B. alcaecerca (Deng, 1997) and B. papiliocerca (Deng, 1997) from Sichuan. On the basis of the original illustrations of the male terminalia (Fan 1988: figs. 8-10), the species $B$. truncata appears as strongly deviating and not a member of a monophyletic $B$. helviana species group. However, two other described species obviously belong here, viz. B. miniatura (Huckett, 1965) from Alaska and northern Canada and B. kitadakeana Suwa, 1998 from Honshu, Japan.

The occurrence of the Botanophila helviana species group in Europe remained unnoticed for a very long time. The reasons might be that they are small and unimpressive anthomyiid flies, rather demanding in their habitat requirements, and tend to have a single, early-season generation. The first European species, discovered simultaneously but independently in Britain and Denmark in the early 1980s by D.M. Ackland and the present author, was Botanophila helviana, described from Denmark by Michelsen (1983), while Ackland (1989) recorded it from England and France. It was reported subsequently from the Czech Republic (Michelsen \& Barták 2001), Spain (Michelsen \& Báez 2002) and from Slovakia and Sweden (Michelsen 2004).

After my description of Botanophila helviana I soon realized that other, closely related species occur in elevated and northern parts of Fennoscandia. On collecting trips in 1983 and 1985 to the Kongsvoll Biological Station, situated in a species-rich, calcareous high-altitude area in south-central Norway, I found no less than 